\title{
Modern Imaging of Myocarditis: Possibilities and Challenges
}

\section{Moderne Bildgebung bei Myokarditis: Möglichkeiten und Herausforderungen}

Authors

Affiliations
B. Baeßler ${ }^{1}$, M. Schmidt ${ }^{2}$, C. Lücke ${ }^{3}$, S. Blazek ${ }^{4}$, P. Ou ${ }^{5}$ D. Maintz ${ }^{1}$, A. C. Bunck ${ }^{1}$

Affiliation addresses are listed at the end of the article.

\section{Key words \\ - cardiac \\ - inflammation \\ - MR imaging \\ - myocarditis \\ - cardiac MRI}

received 20.1.2016

accepted $\quad 4.5 .2016$

Bibliography

Dol http://dx.doi.org/

10.1055/s-0042-108342

Published online: 24.8.2016

Fortschr Röntgenstr 2016; 188:

915-925 @ Georg Thieme

Verlag KG Stuttgart . New York .

ISSN 1438-9029

\section{Correspondence}

Frau Dr. Bettina Baeßler

Department of Radiology, University Hospital of Cologne

Kerpener Str. 62

50937 Cologne

Germany

Tel.: ++49/221/4785060

Fax: ++49/221/4786787

bettina.baessler@uk-koeln.de

\section{Abstract \\ $\nabla$}

Myocarditis is known as the chameleon of cardiac diseases. The symptoms and the course of disease vary greatly so that it is often challenging to establish a diagnosis. Early and accurate diagnosis is of utmost importance, since myocarditis is one of the leading causes of sudden cardiac death in young adults and represents an important precursor to dilated cardiomyopathy. Due to the constraints of the routinely used diagnostic approach, including clinical history and examination, laboratory testing, and electrocardiogram, different imaging modalities have emerged over the last decades as contributors to the noninvasive diagnosis of myocarditis. With this interdisciplinary review we would like to present the current state-of-the-art imaging of myocarditis across all available imaging modalities (i. e., echocardiography, cardiac magnetic resonance, cardiac computed tomography, and nuclear medicine). Furthermore, we present novel imaging techniques that might become useful in the near future for easier and more accurate diagnosis of this highly relevant disease.

Key Points:

- Different imaging modalities are increasingly used in the diagnostic workup of myocarditis.

- Several emerging imaging techniques are currently on the way to becoming part of the clinical routine.

- This review summarizes the diagnostic value of echocardiography, CMR, CT, and nuclear medicine imaging.

- There is special focus on the possibilities and challenges of novel imaging tools within the different modalities.

Citation Format:

- Baeßler B, Schmidt M, Lücke C etal. Modern Imaging of Myocarditis: Possibilities and Challenges. Fortschr Röntgenstr 2016; 188: 915925

\section{Zusammenfassung \\ $\nabla$}

Die Myokarditis ist bekannt als das Chamäleon unter den kardiologischen Erkrankungen: ihre Symptomatik ebenso wie ihr klinischer Verlauf variieren stark, was die Diagnosestellung zu einer großen Herausforderung macht. Eine frühzeitige und korrekte Diagnosestellung ist jedoch von großer Bedeutung, da die Myokarditis eine der Hauptursachen für den plötzlichen Herztod bei jungen Erwachsenen darstellt und nicht selten in einer dilatativen Kardiomyopathie mündet. Aufgrund der Limitationen der routinemäßig eingesetzten diagnostischen Verfahren (bestehend aus Anamnese, klinischer Untersuchung, Blutuntersuchungen und Elektrokardiogramm) sind unterschiedliche bildgebende Verfahren in den letzten Jahrzehnten unverzichtbar für die nicht-invasive Diagnostik der Myokarditis geworden. Ziel der vorliegenden Übersichtsarbeit ist es deshalb, den derzeitigen Stand der Technik in der Diagnostik der Myokarditis über sämtliche bildgebende Modalitäten (Echokardiografie, kardiale Magnetresonanztomografie, kardiale Computertomografie, nuklearmedizinische Untersuchungstechniken) zusammenzufassen und anschließend einen Einblick in junge, noch nicht vollständig klinisch etablierte Techniken zu geben, welche sich in der näheren Zukunft als nützlich im Hinblick auf eine einfachere und genauere Diagnose dieser relevanten Erkrankung erweisen könnten.

Key Points:

- Verschiedene bildgebende Verfahren spielen eine zunehmend wichtigere Rolle in der Diagnostik der Myokarditis.

- Einige neue Bildgebungs-Techniken befinden sich derzeit bereits auf dem Weg in die klinische Routine.

- Dieser Übersichtsartikel gibt einen Überblick über die diagnostische Wertigkeit der Echokardiographie, der kardialen MRT und CT sowie nuklearmedizinischer Verfahren. 


\section{Introduction}

Myocarditis (MC) is defined as an inflammatory disease of the myocardium [1], caused by a broad spectrum of infectious pathogens, cardiotoxins, as well as by hypersensitivity reactions and autoimmune disorders [2]. Although most cases of suspected MC are not linked to a specific etiology, viral infections represent the most common cause in Western Europe and North America [2]. Like the causes of disease, the symptoms vary greatly, ranging from clinically inapparent cases and mild, spontaneously resolving dyspnea and chest pain to arrhythmia, cardiogenic shock or even sudden cardiac death [2]. Due to the clinical diversity and the current lack of widely available and accurate diagnostic tools, the true incidence of $\mathrm{MC}$ remains uncertain [3]. Early and accurate diagnosis, however, is of utmost importance since $\mathrm{MC}$ is one of the leading causes of sudden cardiac death in young adults and represents an important precursor to dilated cardiomyopathy with a corresponding bad prognosis [2].

The diagnosis of MC currently relies on an integrative diagnostic approach including clinical history and examination, laboratory testing (inflammation parameters, myocardial necrosis markers), and electrocardiogram (ECG). However, all these initial clinical tests are often non-specific in the setting of MC [4]. Endomyocardial biopsy (EMB) is regarded as the current diagnostic gold standard for the diagnosis of MC. This highly invasive procedure, however, lacks diagnostic sensitivity due to the often focal disease manifestation and the fluoroscopic $2 \mathrm{D}$ guidance of the bioptome in a $3 \mathrm{D}$ environment, leading to sampling error of myocardial tissue [5], and is associated with relevant patient risks [6]. Moreover, EMB does not provide adequate information about the extension of inflammatory changes and the severity of functional impairment and is often only available in specialized centers. Therefore, the current guidelines recommend EMB only for specific cases with suspected giant cell MC or for clinical courses with predominant signs of heart failure [6].

The diagnostic difficulties have led to increasing importance of different imaging modalities in the setting of MC. With this interdisciplinary review, we would like to present the current stateof-the-art imaging of MC with special emphasis on the presentation of novel imaging techniques that might become useful in the near future for easier and more accurate diagnosis of this highly relevant disease.

\section{Echocardiography \\ $\nabla$}

Echocardiography represents an important imaging modality in the initial diagnostic workup of suspected MC as well as for the follow-up of MC patients. It is widely available, cost-effective and therefore finds broad application as a first-line imaging modality in the clinical routine.

\section{Standard transthoracic echocardiography}

According to the current guidelines of the European Society of Cardiology, all patients with clinically suspected MC should undergo standard transthoracic echocardiography (TTE) at presentation with follow-up examinations if there is any worsening of
Ein spezieller Fokus liegt hierbei auf den Möglichkeiten und Herausforderungen neuer Bildgebungs-Techniken innerhalb der verschiedenen Modalitäten.

hemodynamics [7]. Various changes in quantitative echocardiographic parameters have been described in the diagnostic workup of MC, such as ventricular dysfunction, wall motion abnormalities, diastolic dysfunction or pericardial effusion [7-9]. Impaired right ventricular (RV) function may be observed as well [9]. In an observational study, fulminant MC often leads to a thickened, non-dilated, and hypocontractile left ventricle (LV) $[8,9]$.

However, none of these structural and functional changes is pathognomonic for MC. Standard TTE lacks diagnostic specificity in the setting of MC. In the absence of LV systolic dysfunction or pericardial effusion, MC often remains undetected [10].

\section{Speckle tracking}

Over the last years, the advent of $2 \mathrm{D}$ speckle tracking (ST) has expanded the scope of echocardiography, providing objective noninvasive information on cardiac deformation and regional contractility [10].

In short, speckles (specific natural myocardial acoustic markers), which are equally distributed throughout the myocardium, are tracked with the aid of a computer from frame to frame in the $2 \mathrm{D}$ ultrasound image. Dedicated software allows calculation of the velocity in the myocardial tissue due to the geometric shift of the speckles. With this new technique it is possible to quantify myocardial strain and strain rate in longitudinal, radial, and circumferential directions [11].

Strain parameters are thereby suggested to be more sensitive regarding their diagnostic and potentially prognostic potential compared to conventional functional parameters, e. g. LV ejection fraction. For an example and explanation of the technique, please refer to $\bullet$ Fig. 1.

However, TTE ST depends on a high image quality with a sufficient echocardiographic window to reproduce valid measurements and is limited due to the rather time-consuming acquisition and post-processing [11].

In a study by Hsiao et al., LV circumferential as well as longitudinal strain and strain rate were significantly lower in MC patients compared to healthy controls, and longitudinal strain was shown to exhibit the best diagnostic potential [12]. In addition, the authors showed that event-free survival was significantly related to the tested strain measures [12]. Escher et al. similarly observed reduced $\mathrm{LV}$ global longitudinal strain and strain rate values in MC patients [10] and demonstrated a correlation of LV longitudinal strain parameters with clinically and histologically ongoing myocardial inflammation. Another 2 D ST study observed diffuse impairment of LV longitudinal strain in MC patients with preserved ejection fraction (EF), whereas circumferential strain was only regionally impaired in areas of subepicardial damage [13]. In a study by Khoo et al., impairment of the LV circumferential early diastolic strain rate additionally hinted at impaired LV diastolic function in the setting of MC [14].

Using the 17 segment model of the American Heart Association, another study showed reduced strain corresponding to intramyocardial edema in the basal inferior and inferolateral segments and in the midventricular anterior, anterolateral, and inferolateral segments in comparison to the other segments of the respective slice [15]. 

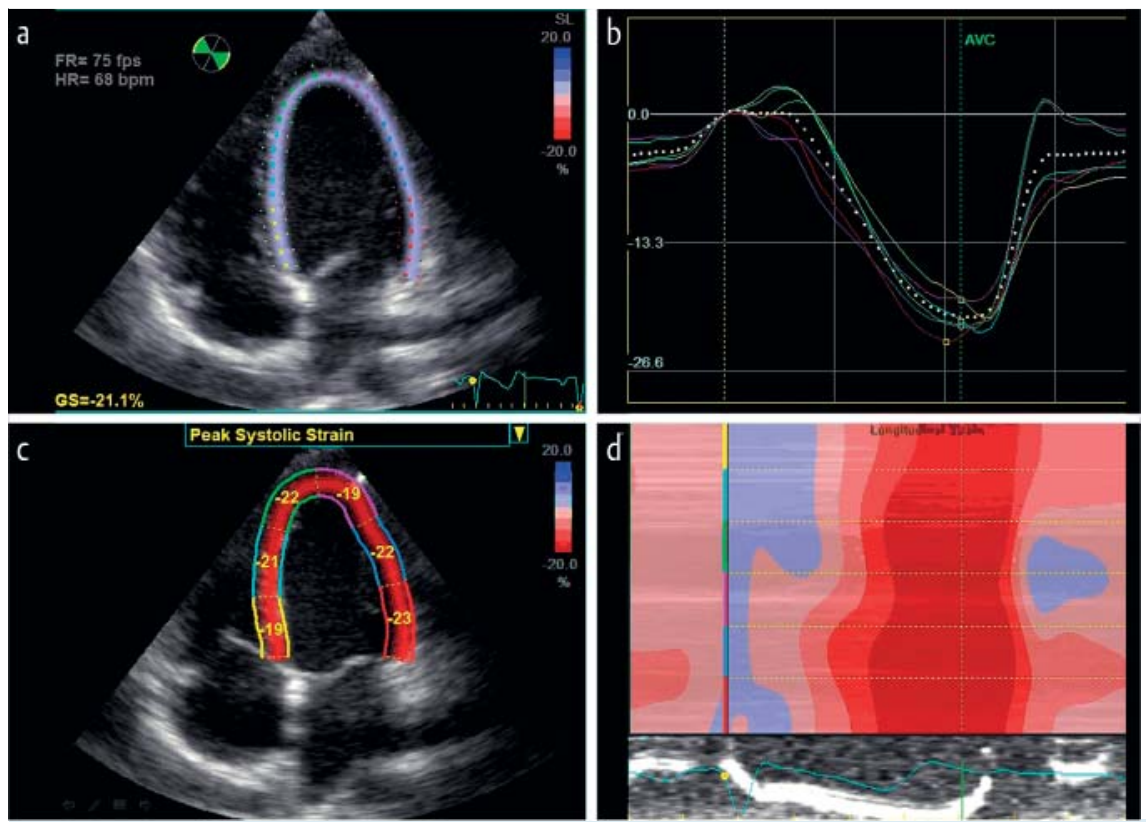

Fig. 1 Echocardiographic analysis of longitudinal strain using speckle tracking. Measurement of longitudinal strain in the 4-chamber view $(4 \mathrm{CH}$, a). The covered segments in $4 \mathrm{CH}$ are depicted color-coded. The graphs in $\mathbf{b}$ represent the percental myocardial shortening/elongation in the corresponding segments over time. The white dotted graph shows the summation of the strain in all covered segments. The closure of the aortic valve is marked with AVC. For calculation of the global strain, additional measurements in 2-chamber and 3-chamber views are required (not shown). In Figure $\mathbf{c}$ the peak strain of the segment is visually associated with the corresponding segment of the $4 \mathrm{CH}$. Figure $\mathbf{d}$ represents the strain graphically over time in the color scale of $\mathbf{a}$ and $\mathbf{c}$.

Abb. 1 Echokardiografische Bestimmung des longitudinalen Strains mittels Speckle Tracking. Dargestellt ist die Messung des longitudinalen Strains im 4Kammerblick (4KB, a). Die erfassten Segmente im 4KB sind farbkodiert dargestellt. In $\mathbf{b}$ wird für die korrespondierenden Segmente die prozentuale myokardiale Verkürzung/Dehnung über die Zeit angegeben. Der Schluss der Aortenklappe ist mit AVC markiert. Die gepunktete weiße Linie entspricht der Summation des Strains in allen dargestellten Segmenten. Für die Berechnung des globalen Strains werden zusätzlich der 2- und 3-Kammerblick benötigt (nicht dargestellt). In Abbildung c wird der Spitzen-Strain des Segmentes visuell dem entsprechenden Segment des 4KB zugeordnet. Abbildung $\mathbf{d}$ stellt den Strain grafisch über die Zeit in der Farbskala aus a und $\mathbf{c}$ dar.
According to these studies in MC patients and to an increasing number of ST studies, strain and strain rate measurements appear to be sensitive indicators for clinical as well as sub-clinical disease and might exhibit potential for prognostic patient evaluation in MC patients and in others with an elevated risk of LV heart failure.

In the future TTE 3 D ST will emerge as an additional imaging method. However, normative values are still to be determined and are not interchangeable with $2 \mathrm{D}$ ST-derived or vendorspecific values [16].

For an overview over the main advantages and disadvantages of all discussed imaging techniques please refer to $\bullet$ Table 1.

\section{Cardiac magnetic resonance}

\section{$\nabla$}

Over the last decades, cardiac magnetic resonance (CMR) has emerged as an important diagnostic tool in the setting of $\mathrm{MC}$ $[17,18]$. According to the EuroCMR and MRCT registry $[19,20]$, MC represents one of the leading indications for a CMR examination. In 2013, a position statement of the European Society of Cardiology working group on myocardial and pericardial diseases [7] recognized $\mathrm{CMR}$ as an independent diagnostic modality in the setting of MC, taking into account its unique capability of combining functional analysis with noninvasive tissue characterization. Besides established diagnostic criteria (the Lake Louise Criteria (LLC) [21]), novel imaging techniques have emerged over the last few years with an inherent potential to revolutionize the noninvasive diagnosis of MC. The most promising tech- niques as well as the state-of-the-art CMR imaging of MC with its principles and limitations will be reviewed in the following sections.

\section{The Lake Louise Criteria: principles and limitations}

Over the last decades, the recommendations of the LLC [21] have been integrated into the standard CMR assessment of MC and are widely used in the clinical routine. The recommendations are based on the presence of two out of three diagnostic criteria ( $\bullet$ Fig. 2): 1) a regional or global myocardial signal intensity (SI) increase on T2-weighted (T2w) images, 2) an increased global myocardial early gadolinium enhancement ratio (EGEr) between myocardium and skeletal muscle in gadolinium-enhanced T1weighted (T1w) images, and 3) at least one focal lesion with non-ischemic regional distribution in inversion recovery-prepared gadolinium-enhanced T1w images (late gadolinium enhancement, LGE).

The SI increase on T2w images can either be analyzed visually or can be quantified by an SI ratio of myocardium over skeletal muscle of $\geq 1.9$ ("T2-ratio" / "edema ratio") $[22,23]$. The largest to date meta-analysis dealing with the T2-ratio showed an average sensitivity of $70 \%$ and an average specificity of $71 \%$ for detecting myocardial edema [21]. The threshold of $\geq 1.9$, however, has been established using a body coil in combination with a T2w black blood sequence [22] and only limited validation studies of this threshold have been performed with respect to different coils, scanners, field strengths and sequence types [24]. In addition, systemic inflammatory conditions in which skeletal muscles may equally be involved limit the sensitivity of diagnostic ap- 
Table 1 Main advantages and disadvantages of different imaging techniques.

\begin{tabular}{|c|c|c|c|}
\hline method & technique & main advantages & main disadvantages \\
\hline \multirow[t]{2}{*}{ echocardiography } & TTE & $\begin{array}{l}\text { widely available, cost-effective, no radiation, } \\
\text { no need for contrast administration }\end{array}$ & $\begin{array}{l}\text { observer-dependent, sub-optimal echocardiographic } \\
\text { windows (especially for RV), no tissue characterization }\end{array}$ \\
\hline & speckle tracking & $\begin{array}{l}\text { see TTE } \\
\text { allows assessment of active and passive strain, strain } \\
\text { parameters more sensitive compared to echocardio- } \\
\text { graphic "standard" parameters }\end{array}$ & $\begin{array}{l}\text { see TTE } \\
\text { not yet fully integrated into clinical routine, not widely } \\
\text { available }\end{array}$ \\
\hline \multirow[t]{6}{*}{ MRI } & Lake Louise criteria & $\begin{array}{l}\text { qualitative tissue characterization combined } \\
\text { with functional and morphological imaging } \\
\text { ("one-stop shop") }\end{array}$ & $\begin{array}{l}\text { not widely available, expensive, contrast administration } \\
\text { needed }\end{array}$ \\
\hline & T2 mapping & $\begin{array}{l}\text { quantitative tissue characterization (edema) without } \\
\text { the need for contrast administration, increased diag- } \\
\text { nostic performance compared to Lake Louise criteria }\end{array}$ & $\begin{array}{l}\text { lack of standardization, great inter-individual variability } \\
\text { of normal values, differences in myocardial T2 intro- } \\
\text { duced by sequence design and field strength }\end{array}$ \\
\hline & native T1 mapping & $\begin{array}{l}\text { quantitative tissue characterization (edema and fibrosis) } \\
\text { without the need for contrast administration, increased } \\
\text { diagnostic performance compared to Lake Louise criteria }\end{array}$ & $\begin{array}{l}\text { lack of standardization, many different sequences } \\
\text { available, differences in myocardial T1 introduced by } \\
\text { sequence and field strength }\end{array}$ \\
\hline & ECV mapping & $\begin{array}{l}\text { quantitative tissue characterization, thought to be sen- } \\
\text { sitive for alterations of the extracellular space caused by } \\
\text { edema and fibrosis, increased diagnostic performance } \\
\text { compared to Lake Louise criteria }\end{array}$ & $\begin{array}{l}\text { see native T1 mapping } \\
\text { need for contrast administration }\end{array}$ \\
\hline & DWI & $\begin{array}{l}\text { thought to be more sensitive compared to T2w imaging } \\
\text { in the presence of myocardial edema, no need for con- } \\
\text { trast administration }\end{array}$ & $\begin{array}{l}\text { still technically challenging due to motion, } \\
\text { susceptibility or pulsation artifacts }\end{array}$ \\
\hline & feature tracking & $\begin{array}{l}\text { retrospective analysis of cine images, allows } \\
\text { assessment of active and passive strain, strain param- } \\
\text { eters more sensitive compared to "standard" functional } \\
\text { parameters }\end{array}$ & $\begin{array}{l}\text { dedicated software needed (expensive), lack } \\
\text { of standardization, reproducibility issues }\end{array}$ \\
\hline $\begin{array}{l}\text { computed } \\
\text { tomography }\end{array}$ & $\begin{array}{l}\text { cardiac } \mathrm{CT} / \\
\text { dual source } \mathrm{CT} / \\
\text { spectral CT }\end{array}$ & $\begin{array}{l}\text { of special interest in patients with contraindications } \\
\text { to CMR or in centers where CMR is not available } \\
\text { Additional possibility of coronary artery examination } \\
\text { to definitely rule out coronary artery disease } \\
\text { Fast technique } \\
\text { Better temporal and spatial resolution when } \\
\text { compared to MRI }\end{array}$ & $\begin{array}{l}\text { radiation exposure (depending on scanner type and } \\
\text { protocol) } \\
\text { need for iodine contrast administration } \\
\text { delayed contrast-enhanced imaging with CT not } \\
\text { routinely performed } \\
\text { dual source / spectral CT scanners not widely available }\end{array}$ \\
\hline \multirow[t]{2}{*}{$\begin{array}{l}\text { nuclear medicine } \\
\text { imaging }\end{array}$} & SPECT & $\begin{array}{l}\text { widely available, qualitative and semi-quantitative im- } \\
\text { age analysis, observer-independent }\end{array}$ & $\begin{array}{l}\text { not routinely used in clinical practice b/o limited num- } \\
\text { ber of publications with usually small patient numbers, } \\
\text { sensitivity of only } 75 \% \text {, perfusion defects also seen in } \\
\text { coronary artery disease and therefore not specific for } \\
\text { myocarditis, radiation exposure }\end{array}$ \\
\hline & FDG-PET & $\begin{array}{l}\text { qualitative and quantitative image analysis, } \\
\text { observer-independent }\end{array}$ & $\begin{array}{l}\text { dedicated cardiac software needed (expensive), proto- } \\
\text { cols for imaging established but potentially time-con- } \\
\text { suming, diabetic patients are a special challenge, radia- } \\
\text { tion exposure, expensive }\end{array}$ \\
\hline
\end{tabular}

proaches in which SI is normalized to the skeletal muscle and can lead to false-negative results. This and several technical limitations of T2w imaging in the heart have relativized the diagnostic usefulness of the first criterion over the last few years [24] and novel methods (e.g. T1 and T2 mapping) are currently being evaluated as potential alternative approaches to overcome these limitations, as further discussed below.

Similar problems arise for the second diagnostic criterion, the EGEr. An EGEr $\geq 4$ is regarded as pathological [22]. This threshold was also established using a body coil and until now, only limited validation studies of the threshold with respect to different coils, field strengths and scanner types are known [24]. As in the case of the T2-ratio, systemic inflammatory conditions might lead to false-negative results when normalizing the pre- and post-gadolinium SI to skeletal muscles. Therefore, an absolute myocardial SI increase between pre-gadolinium and post-gadolinium images of more than $45 \%$ is recommended to be used as a threshold when skeletal muscle involvement appears to be likely [25].
LGE, which serves as the third criterion, represents a robust technique for imaging myocardial necrosis and fibrosis. A predominant subepicardial or intramural location of delayed contrast accumulation is commonly seen in MC, although transmural patterns might also occur [26]. Recently, Grün et al. have stated not only a diagnostic but also a prognostic value for LGE imaging in $\mathrm{MC}$ [27].

The presence of LV dysfunction or pericardial effusion provides additional supportive evidence for the presence of MC according to the LLC [21], although they do not represent independent diagnostic criteria. Nevertheless, according to a large patient study by Schumm et al., a normal CMR study, represented by normal cardiac function and the absence of LGE, provided prognostic information with respect to cardiac mortality and morbidity [28].

\section{T2 mapping}

Qualitative T2w imaging as recommended by the LLC is known to suffer from various limitations, e.g. regional myocardial signal variations caused by phased-array coils, high signal from stag- 


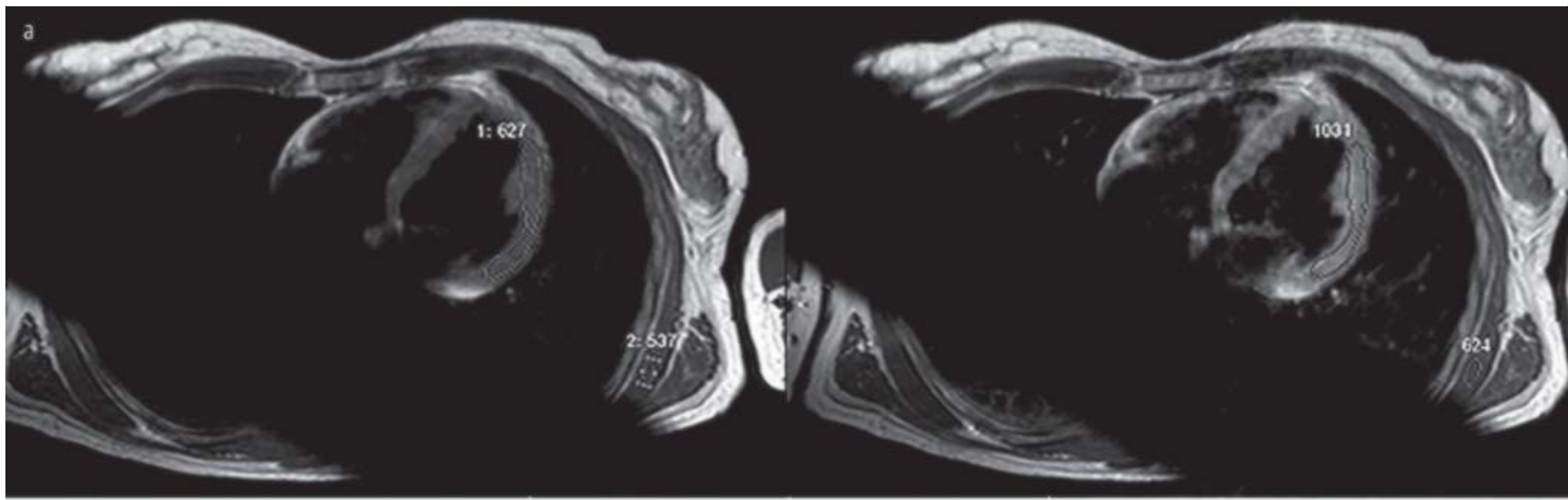

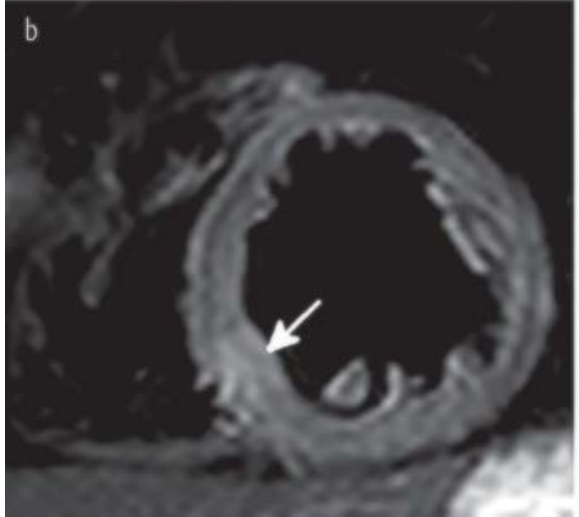

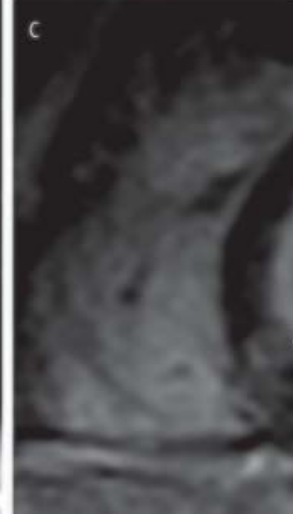

Fig. 2 Classic Lake Louise criteria. Case of a 32-year-old male presenting with chest pain, elevated troponin levels, and normal coronary angiogram. CMR images show a pathological early gadolinium enhancement ratio of $4.1 \mathbf{a}$ and focal myocardial edema in the midventricular septal wall (b, arrow) with corresponding late gadolinium enhancement, which can be depicted on a midventricular short axis slice (c, arrow) and on a four-chamber view (d, arrow). With three out of three Lake Louise criteria being positive in this case, the diagnosis of acute myocarditis was confirmed.

nant blood ("slow flow" artifact), which leads to difficulties in differentiating edema from sub-endocardial blood, throughplane motion and the qualitative nature of image interpretation relying on relative regional SI differences [29].

Recently, T2 mapping has been introduced as a quantitative approach to edema imaging and might allow more sensitive detection of diffuse as well as subtle changes in myocardial T2 relaxation times $[29,30]$. T2 parametric maps display T2 relaxation times pixel-by-pixel and are basically generated after acquisition of a series of images with various echo times, from which a T2 decay curve is derived ( $\bullet$ Fig. 3) [31]. There have been several attempts and different approaches to bring T2 mapping to the clinical routine for more sensitive detection of myocardial edema in the setting of MC ( Fig. 4) [30, 32, 33].

Despite these and other approaches, there are still some hurdles to be overcome for the integration of $\mathrm{T} 2$ mapping into the clinical routine. One of its main challenges is the high intra- and interindividual variability of myocardial T2, leading to potential difficulties in discriminating between health and disease. While T2 is an inherent tissue property, a recent study in healthy volunteers demonstrated that myocardial $\mathrm{T} 2$ varies significantly depending on the sequence type and field strength used, leading to variations in T2 times of almost $20 \mathrm{~ms}$ (with the mean myocardial T2 values being between 44 and $59 \mathrm{~ms}$ ) [34]. Considering that the difference between remote and edematous myocardium has been reported to be in the range of $10-20 \mathrm{~ms}$ [30], the previously defined cut-offs have to be applied carefully and only when the same sequence parameters and field strength are used.

Moreover, the previous approaches to define cut-off values in order to detect myocardial edema have a common major limitation: averaging myocardial T2 over many segments or even over the whole heart does not take into account the often focal nature of MC. Small edematous changes, which can be distributed diffusely or focally throughout the whole myocardium thereby involving only small parts of many different segments, may easily be overlooked when choosing an "averaging" approach.

A recently published study therefore proposed a novel approach to diagnose myocardial inflammation by mapping tissue inhomogeneity [35]. Our study group introduced a set of novel parameters, which were derived from absolute myocardial T2 as well as from the standard deviation originating when averaging all pixels within one myocardial segment for segmental T2 quantification ("Pixel-SD"). These novel parameters were designed to reflect the main aspects of focal disease manifestation in MC without missing diffuse disease. Moreover, these parameters promise to be less dependent on the overall level of myocardial T2, which, as outlined, may vary significantly between individuals and appear to be determined by additional non-diseaserelated factors. Future validation studies will have to show if this 
novel approach will be able to overcome the hurdles of T2 mapping for its integration into the clinical routine.

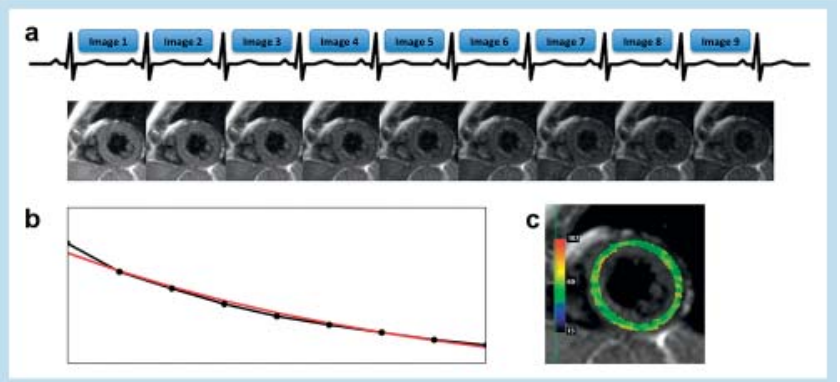

Fig. 3 Technical principle of cardiac mapping based on the example of T2 mapping. Technical principle of $\mathrm{T} 2$ mapping, based on acquisition with a gradient-echo spin echo (GraSE) sequence [62]. A set of nine images is acquired using nine different echo times within one breath-hold $\mathbf{a}$. The acquired images are then processed to fit the T2 decay curve $\mathbf{b}$ at each pixel to yield a T2 map c. Various acquisition schemes and sequences are available for $\mathrm{T} 2$ as well as for $\mathrm{T} 1$ mapping, but all of them share the same principle of acquiring a set of images with different echo or repetition times and fitting them to the $\mathrm{T} 2$ or $\mathrm{T} 1$ decay curve in order to obtain $\mathrm{T} 2$ or $\mathrm{T} 1$ maps.

Abb. 3 Technisches Prinzip des kardialen Mapping am Beispiel des T2Mapping. Technisches Prinzip des T2-Mapping, basierend auf der Akquisition mittels einer Gradienten-Echo Spin-Echo (GraSE) Sequenz [62]. Neun Bilder mit unterschiedlichen Echozeiten werden innerhalb eines Atemanhalters akquiriert a. Die akquirierten Bilder werden anschließend prozessiert und Pixel-basiert an die T2-Relaxationskurve angefittet $\mathbf{b}$. Auf diesem Wege erhält man die T2-Map c. Es existieren verschiedenste Akquisitionsschemata und Sequenzen für das kardiale T2 als auch T1-Mapping. Allen gemeinsam ist jedoch das technische Prinzip der Aufnahme verschiedener Bilder zu unterschiedlichen Echo- bzw. Repetitionszeiten, dem anschließenden Anfitten an die T2- bzw. T1-Relaxationskurve und dem Generieren von T2- bzw. T1-Maps.

\section{T1 mapping}

Like T2 relaxation times, T1 relaxation times can also be prolonged in the inflamed myocardium. An elegant way to measure T1 times in the myocardium is T1 mapping, which is technically equivalent to T2 mapping. There are multiple ways to assess T1 times in the myocardium with inherent advantages and disadvantages with respect to the accuracy and precision of the determined T1 time [36]. In the clinical routine, precision is more important than accuracy in determining $\mathrm{T} 1$ times with respect to the differentiation of cardiac diseases. Therefore, inversion recovery techniques such as modified Look-Locker sequences (MOLLI) have been widely introduced in clinical research [37]. Two types of T1 mapping prevail: 1) native T1 mapping, and 2) extracellular volume fraction (ECV) mapping [38] ( $\bullet$ Fig. 5). The ECV is calculated from the change in the $\mathrm{T} 1$ relaxation rate in the blood pool and myocardium between pre- and post-contrast imaging, calibrated with the blood hematocrit [39]. The ECV is thought to be sensitive to the distribution of the myocardium into its cellular and interstitial compartments, thereby reflecting the size of the interstitium, which can be altered in a variety of pathologic conditions [39]. In contrast to LGE imaging, native $\mathrm{T} 1$ and ECV are thought to be more sensitive to diffuse changes in the myocardium in the setting of myocardial inflammation and/or remodeling, as they do not rely on relative changes in signal intensities inside the myocardium.

So far, several studies have shown the potential utility of T1 mapping in the diagnosis of MC. In 2013, Ferreira et al. demonstrated that patients suffering from acute MC had higher native myocardial T1 than healthy controls at $1.5 \mathrm{~T}$ [40]. In a large patient study Hinojar et al. demonstrated the great potential of native T1 for detecting $\mathrm{MC}$, and in this study a combination of native $\mathrm{T} 1$ and LGE performed even better [41]. In addition, the authors established cut-offs for native T1 in order to discriminate acute from chronic MC, thereby demonstrating a steady decline in native T1 as inflammation resolved. Somewhat controversially, a study by Radunski et al. stated that not native T1 but rather a combination of ECV and LGE significantly improved the diagnostic accuracy of
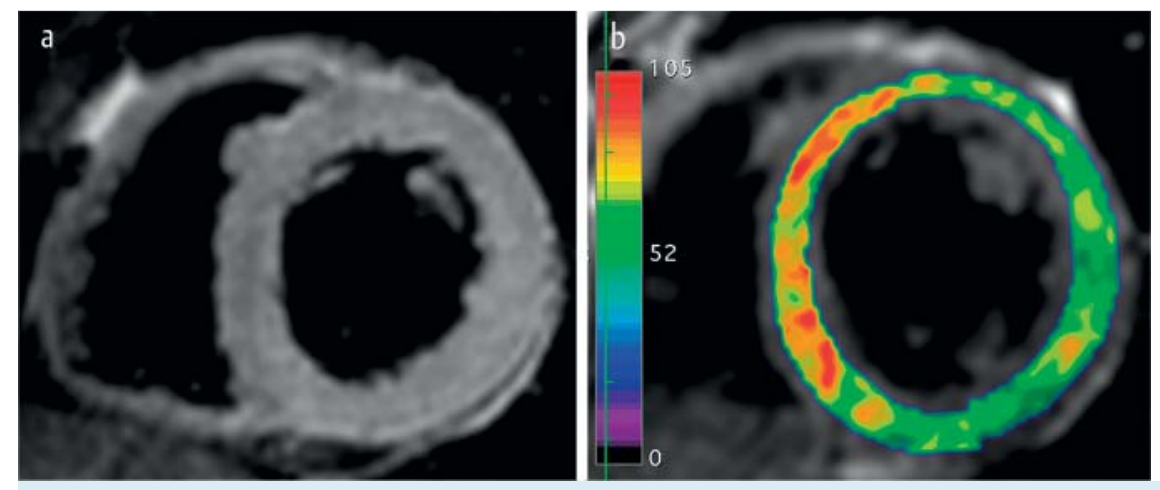

Fig. 4 Incremental value of T2 mapping in a case of diffuse myocardial edema. Case of a 36-year-old woman with severe myositis of the thighs and signs of systemic inflammation, presenting with chest pain and a large pericardial effusion. CMR was performed in order to exclude myocarditis. T2-weighted black blood images a show an increased left ventricular wall thickness, but no focal areas of increased signal intensity. The $\mathrm{T} 2$ ratio was normal (1.4). In contrast, T2 mapping b revealed highly pathological T2 values of up to $110 \mathrm{~ms}$ especially in the entire septum, but also focal spots of high $\mathrm{T} 2$ values in the lateral wall. These finding indicate diffuse myocardial edema, which had been missed on conventional T2-weighted imaging.
Abb. 4 Diagnostischer Zusatznutzen des T2-Mapping im Falle eines diffusen myokardialen Ödems, Fall einer 36-jährigen Patientin mit schwerer Oberschenkel-Myositis und Zeichen einer systemischen Inflammation, welche sich mit Thoraxschmerzen und einem ausgedehnten Perikarderguss vorstellte. Eine kardiale MRT-Untersuchung wurde zum Ausschluss einer Myokarditis durchgeführt. T2-gewichtete Black-Blood-Bilder a zeigen ein verdicktes linksventrikuläres Myokard, jedoch keine fokalen Areale erhöhter Signalintensität. Die T2-Ratio lag im Normbereich (1.4). Im Gegensatz dazu zeigt das T2-Mapping b hochgradig pathologische T2-Werte bis zu $110 \mathrm{~ms}$ insbesondere im gesamten Septum, jedoch auch in der Lateralwand. Diese Befunde waren mit einem diffusen myokardialen Ödem vereinbar, welches in der konventionellen T2-Bildgebung der Diagnose entgangen war. 

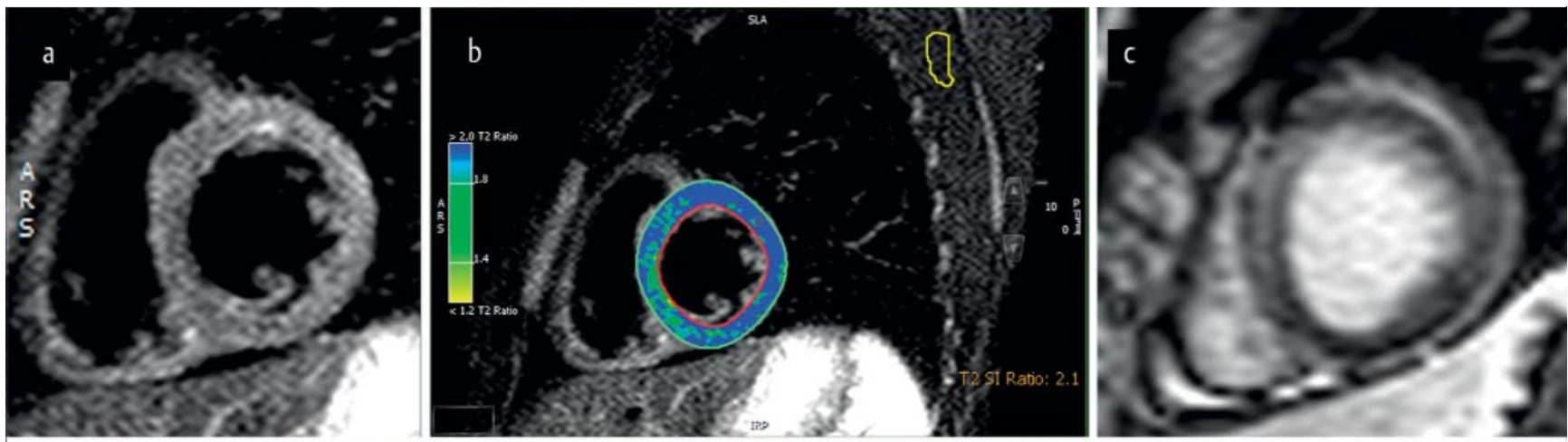
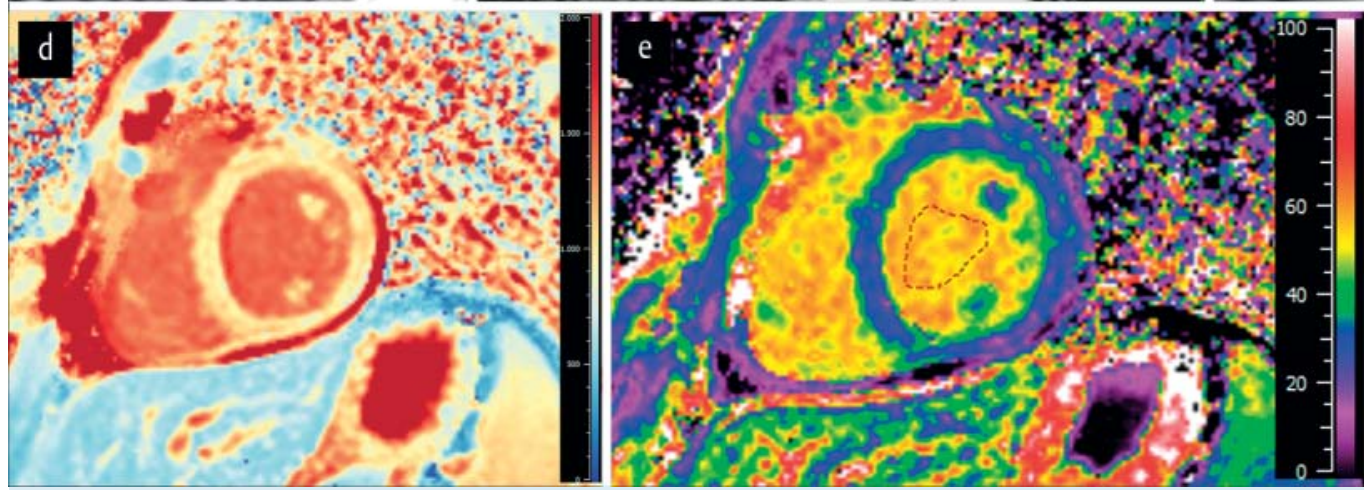

Fig. 5 T1/ECV mapping in a case of biopsy-proven acute myocarditis. Case of a 24-year-old male presenting with respiratory-dependent, not stressrelated chest pain. The patient had a history of recent gastrointestinal infection and a cold. Coronary artery disease was excluded by coronary angiography. Fat-suppressed T2w sequences showed diffuse edema of the basal anterolateral wall a and the apical segments. Myocardial inflammation was assessed with the classic LLC (relative water content 2.1 b, EGEr = 9.1). LGE showed subepicardial enhancement in the basal anterolateral wall c and mid-wall enhancement in the apical segments. Native T1 was prolonged to $1107 \mathrm{~ms}$ d, and the ECV was elevated to $36 \%$ e. EMB showed a moderately active chronic parvovirus B19 MC. Evaluation of classic sequences was performed with cmr42 (Circle, Leiden, The Netherlands), T1- and ECV-maps generated with Mapmaker (Medis medical imaging systems, Leiden, The Netherlands).
Abb. 5 T1-ECV-Mapping bei bioptisch gesicherter Myokarditis. Ein Patient (24 Jahre, männlich) stellte sich mit atemabhängigen, aber nicht belastungsassoziierten Thoraxschmerzen nach vorausgegangenem gastrointestinalen Infekt und Schnupfen vor. Der Ausschluss einer koronaren Herzerkrankung erfolgte mittels Herzkatheter-Untersuchung. In der fettsupprimierten T2-gewichteten Sequenz zeigt sich ein diffuses Ödem der basalen Anterolateralwand a sowie der apikalen Segmente. Die myokardiale Inflammation konnte mittels der klassischen Lake-Louise-Kriterien bestätigt werden (relativer Wassergehalt 2.1 b, relatives Early Enhancement $=9.1$ ). Die Analyse der Late-Enhancement-Sequenzen ergab eine subepikardiales Kontrastmittelanreicherung basal anterolateral sowie ein streifiges intramyokardiales bis subepikardiales Late Enhancement der apikalen Segmente. Die native T1-Zeit war auf bis zu 1107 ms verlängert d, das extrazelluläre Volumen (ECV) auf 36 \% erhöht e. Die Endomyokardbiopsie ergab eine mäßiggradig aktive chronische Parvovirus B19-Myokarditis. Die Evaluation der klassischen Sequenzen und der Lake-Louise-Kriteren erfolgte mit cmr42 (Circle, Leiden, Niederlande), die Generierung der T1- und ECV-Maps mit Mapmaker (Medis medical imaging systems, Leiden, Niederlande).
CMR compared to LLC [42], and recently, a case report of biopsyproven $\mathrm{MC}$ reported that both native $\mathrm{T} 1$ and ECV were superior to LLC in diagnosing MC.

Taken together, it remains unclear which parameter (native T1, $\mathrm{ECV}$, combined or not combined with LGE) will ultimately provide the best diagnostic performance for MC. Future prospective patient studies will have to solve this issue. With respect to a comparison of T1 mapping with T2 mapping in the setting of $\mathrm{MC}$, there is currently only one study showing superior diagnostic performance for T2 mapping over T1 mapping [43]. The comparison of these novel methods in a multiparametric approach also needs further patient studies.

\section{Diffusion-weighted imaging}

Over the last few years, diffusion-weighted imaging (DWI) has increasingly been recognized as an interesting diagnostic tool in the heart. However, despite technical improvements such as more powerful gradients and phased-array coils and the development of fast imaging techniques, DWI of the heart remains technically challenging due to motion, susceptibility or pulsation artifacts [44].

A small set of studies, however, has addressed the field of DWI in the heart in order to establish a more sensitive diagnostic tool for edema detection in the setting of MC. In 2013, Potet et al. described for the first time that a low b-value diffusion-weighted echo-planar imaging sequence might be a sensitive alternative to T2w imaging for detecting myocardial edema in MC patients [45]. In addition, they showed first results that DWI might be even more sensitive compared to $\mathrm{T} 2 \mathrm{w}$ imaging in the presence of myocardial edema ( $\bullet$ Fig. 6 ). Further studies should address and validate this interesting approach, as DWI represents a fast technique without the need for contrast administration, which could provide additional information in the setting of MC.

\section{Feature tracking-based strain analysis}

An additional alternative diagnostic approach in the setting of MC is CMR feature tracking (FT)-based myocardial strain analysis, which represents a comparable technique to echocardiographic 

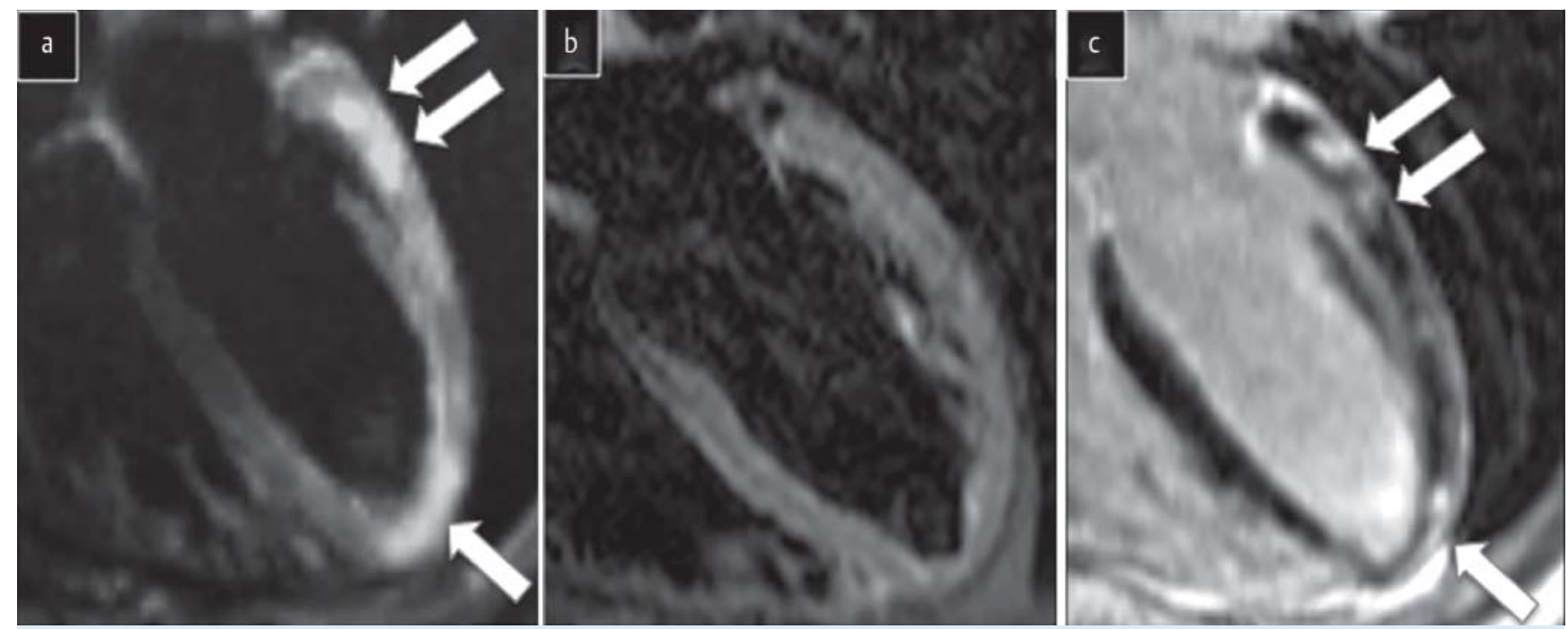

Fig. 6 Diffusion-weighted imaging (DWI) in acute myocarditis. DWI a, T2weighted STIR $\mathbf{b}$, and late gadolinium enhancement $\mathbf{c}$ images acquired in a four-chamber plane in a patient with suspected acute myocarditis. Arrows on a show myocardial high signal areas located within the basal part of the lateral wall as well as in the apex. $\mathbf{b}$ did not reveal any local increase of signal intensity. The arrows on c show focal enhancement located in the same areas as in a, underlining the potential of DWI in detecting myocardial edema. Courtesy of Jean-François Deux, Department of Radiology, Henri Mondor Hospital, University Paris Est, Créteil, France.
Abb. 6 Diffusions-gewichtete Bildgebung (DWI) bei akuter Myokarditis. DWI a, T2-gewichtete STIR b und Late Enhancement c Bilder, aufgenommen im Vierkammerblick bei einem Patienten mit Verdacht auf akute Myokarditis. Die Pfeile in a weisen auf Areale mit erhöhter Signalintensität in der basalen Lateralwand sowie im Apex. b zeigte keinen lokalen Anstieg der Signalintensität. Die Pfeile in c zeigen auf ein fokales Late Enhancement in korrespondierenden Arealen zu a, was das Potential der DWI für die Diagnostik des myokardialen Ödems unterstreicht. Mit freundlicher Genehmigung von Jean-François Deux, Institut für Radiologie, Henri Mondor Hospital, Universität Paris Est, Créteil, France.
ST. FT allows tracking of tissue voxel motion from routinely acquired cine images and derivation of myocardial strain parameters without the need for the acquisition of additional sequences [46]. In contrast to ST, which tracks randomly generated myocardial speckle artifacts in the echo image throughout the cardiac cycle [47], the FT algorithm is based on tracking of the epi- or endocardial borders [46].

A recently published study could show the potential diagnostic value of a combined left and right ventricular strain analysis in acute MC even when EF was preserved, thereby highlighting a potential role for the often "forgotten" RV in the pathophysiology of MC [48]. Moreover, the study demonstrated the diagnostic value of RV strain analysis in patients with clinically diagnosed acute MC showing an otherwise completely inconspicuous CMR study. Therefore, FT may prove advantageous in cases of clinical MC where traditional CMR techniques are inconclusive.

\section{Computed Tomography}

$\nabla$

Although CMR is the reference noninvasive technique for the diagnostic assessment of MC, preliminary investigations have introduced cardiac computed tomography (CT) as an interesting alternative for visualizing myocardial damage in patients with clinically suspected MC [49]. Cardiac CT is particularly useful in the setting of acute chest syndrome for differentiating myocardial ischemia from acute myocarditis [50]. Indeed, in a simple and rapid examination CT provides a comprehensive evaluation of both the coronary arteries and myocardial tissue characteristics. In practice, first-pass CT acquisition allows assessment of the coronary anatomy as well as of LV enhancement so that significant coronary stenosis is revealed by subendocardial hypoperfusion. The delayed CT acquisition is performed 3 to 5 minutes later without any reinjection of contrast medium, allowing imaging of iodine uptake on late contrast-enhanced images in a similar fashion as CMR. The latest generation of CT machines has closed a technological gap with the principle of spectral imaging. The technology is based on the use of multi-energy imaging obtained either by single or dual source emission. It allows collection of the entire range of attenuation curves of the different materials included in the acquired volume, thus allowing tissue decomposition based on the X-ray attenuation at different photon energies emitted by the tube. Iodine is well recognized by its specific curve attenuation according to its physical and chemical composition so that it is easily possible to extract the iodine map [51]. Delayed iodine contrast-enhanced imaging reveals the inflamed area showing increased uptake of iodine contrast agent in the interstitial space ( $\bullet$ Fig. 7) $[52,53]$. It is also possible to objectively quantify the iodine concentration in the inflamed tissue ( $\bullet$ Fig. 7) [52, 53]. Moreover, a recently published study could demonstrate for the first time the feasibility of cardiac CT for ECV quantification by dynamic equilibrium CT in cardiac amyloidosis [54] and highlighted some advantages of CT over CMR in this setting, one of them being the simple linear relationship between attenuation and iodine concentration as opposed to the nonlinear effect on the relaxivity of hydrogen following the administration of gadolinium.

Further evaluation is needed for these interesting novel techniques, which will determine whether cardiac CT could be an alternative to MRI for the diagnosis of acute MC. It might be of special interest in patients with contraindications to CMR or in centers where CMR is not widely available. Furthermore, a potential advantage of cardiac CT compared to MRI could be the additional possibility of a validated coronary artery examination to definitely rule out coronary artery disease. 

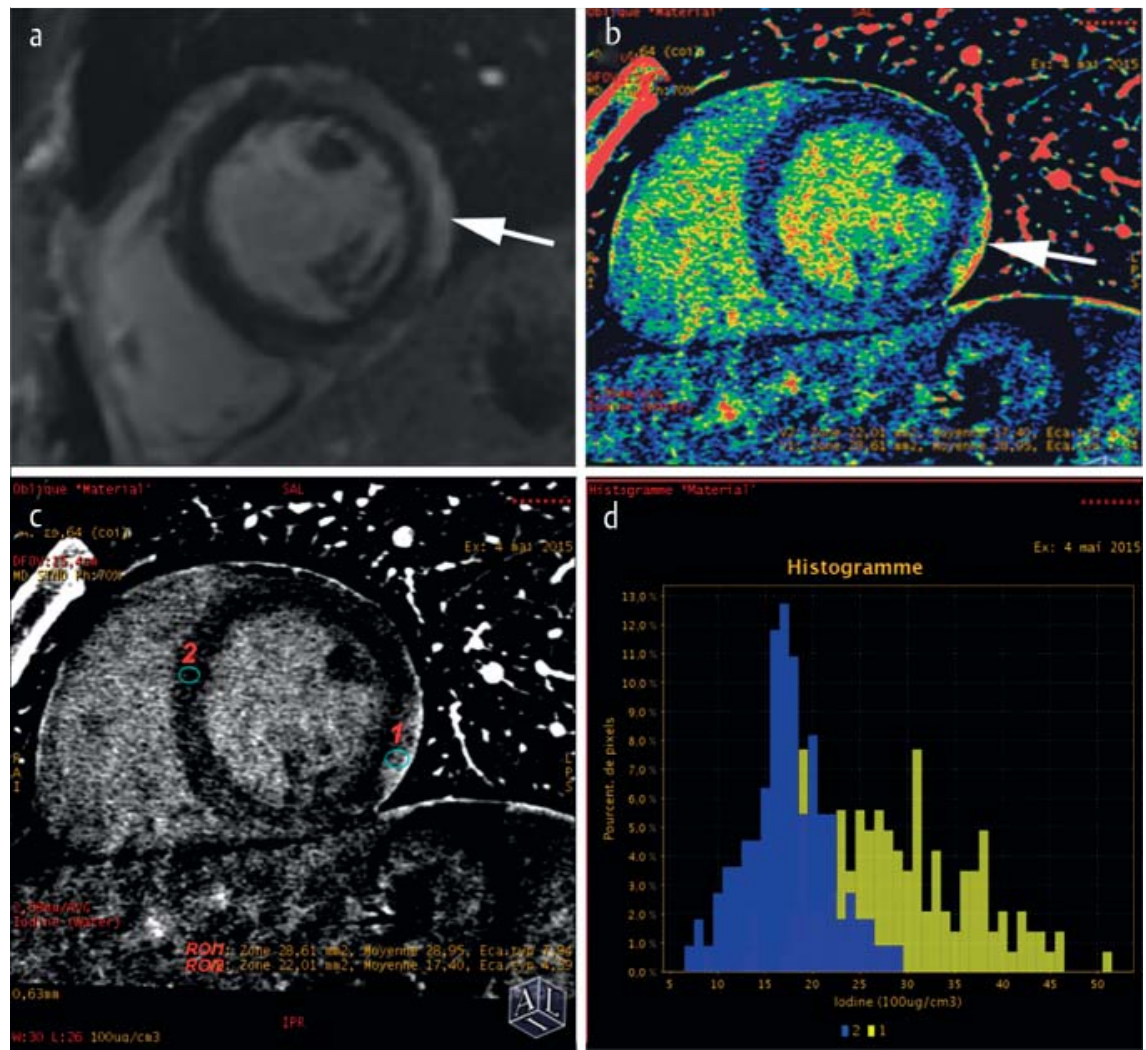

Fig. 7 Cardiac CT: lodine map extraction obtained from delayed contrastenhanced imaging and quantification of myocardial iodine concentration. Myocardial injury typical for myocarditis seen in the subepicardial layer of the inferolateral segment of the LV appearing as a hyperintense area (arrow) on LGE imaging a. Corresponding iodine uptake can be depicted in the same area on delayed iodine imaging $\mathbf{b}$. The iodine concentration in this region (ROI 1) is measured at $28.9 \mu \mathrm{g} / \mathrm{cm} 3 \mathrm{c}$, whereas it is measured only at $17.40 \mu \mathrm{g} / \mathrm{cm} 3$ in the normal myocardium in the interventricular septum (ROI 2). d shows the corresponding histogram demonstrating the clear separation of the density of the previously measured ROIs (ROI 1 density in yellow corresponding to high concentration of iodine in the inferolateral segment of the LV; ROI 2 density in blue corresponding to low concentration of iodine in the septum).

Abb.7 Kardiale CT: Jod-Map-Extraktion und Quantifizierung der myokardialen Jod-Konzentration. Die myokardiale Läsion in der subepikardialen Region des linksventrikulären inferolateralen Segmentes imponiert in der MRT-Late-Enhancement-Bildgebung als hyperintense Region (Pfeil; a). Auf der mittels Kontrastmittel-verstärker CT-Technik aufgenommenen Jod-Map ist in korrespondierender Lokalisation eine verstärkte Jod-Aufnahme nachweisbar b und die Jod-Konzentration wird mit $28.9 \mu \mathrm{g} / \mathrm{cm} 3$ gemessen (c; ROI 1), während sie im normalen Myokard im interventrikulären Septum (ROI 2) lediglich $17.40 \mu \mathrm{g} / \mathrm{cm} 3$ beträgt. $\mathbf{d}$ zeigt das korrespondierende Histogramm mit einer klaren Trennung der Dichtewerte der zuvor gemessenen ROIs (ROI 1: die Dichtewerte in gelb entsprechen der hohen Jod-Konzentration im inferolateralen Segment; ROI 2: die Dichtewerte in blau entsprechen der geringeren Jod-Konzentration im interventrikulären Septum).

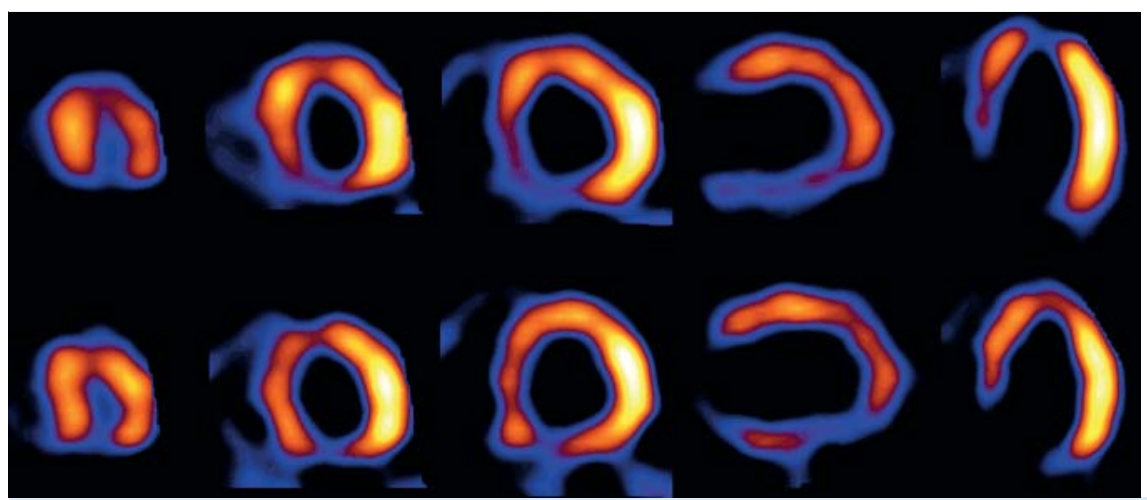

Fig. 8 Myocarditis-induced perfusion abnormalities on TI-201-SPECT. Apical, mid-ventricular and basal short-axis views as well as vertical and horizontal long-axis views after injection of $74 \mathrm{MBq}$ Tl-201-chloride at rest (10 min p. i.; upper row) and after reperfusion ( 3 h p. i.; lower row) demonstrating perfusion defects predominantly in the inferior wall after myocarditis. Coronary artery disease had been excluded.
Abb. 8 Myokarditis-induzierte Perfusionsdefekte in der TI-201-SPECT. Apikale, mittventrikuläre und basale Kurzachsenschnitte sowie jeweils ein vertikaler und horizontaler Langachsenschnitt nach Injektion von $74 \mathrm{MBq}$ TI-201-Chlorid in Ruhe (10 min. p. i.; obere Bildreihe) und nach Reperfusion ( 3 h p. i.; untere Bildreihe). Bei klinisch diagnostizierter Myokarditis zeigen sich Perfusionsdefekte insbesondere in der Hinterwand des linken Ventrikels. Eine koronare Herzkrankheit war vorher ausgeschlossen worden. 


\section{Nuclear medicine imaging}

While recent progress has been achieved with nuclear imaging techniques to diagnose infective endocarditis or cardiac devicerelated infections, there is a paucity of nuclear imaging data concerning the diagnosis of MC.

It has long been known that a patchy uptake pattern seen on myocardial perfusion scintigraphy can be indicative of MC ( Fig. 8). This sign, however, has an insufficient sensitivity of about 75\% [55] to be used alone for the diagnosis of MC and therefore, the current German guidelines on myocardial perfusion single photon emission computed tomography (SPECT) [56] do not include the indication of MC.

Recently, increasing relevance has been reported for positron emission tomography (PET) in combination with CT or MRI for the diagnosis of MC and especially for sarcoidosis, which represents a special subtype of MC. A special challenge for cardiac imaging by fluorodeoxyglucose (FDG)-PET, however, is the variable physiologic uptake of FDG within the heart, depending on the length of the fasting period [57]. There are several approaches to stimulate myocardial glucose metabolism with either oral or IV glucose loading [58]. In addition, the time between the onset of MC and FDG-PET has to be taken into account [59]. According to a small set of case studies, a patchy FDG uptake pattern might be typical in the setting of MC $[60,61]$.

Due to the lack of reliable data, larger studies are needed to better define the clinical value of FDG PET/CT and FDG PET/MRI for the diagnosis of MC.

\section{Conclusion}

$\nabla$

Different imaging modalities are increasingly used in the noninvasive diagnosis of MC. Especially some of the novel techniques discussed above have the potential to revolutionize the future diagnostic work-up of MC and significant research efforts are currently being undertaken in order to overcome the hurdles for establishing one or the other technique in the clinical routine.

ST-based myocardial strain imaging is on the way of becoming part of the echocardiographic routine protocol and its potential prognostic role needs assessment in further patient studies. CMR with its inherent potential to combine functional analysis with noninvasive tissue characterization in a "one-stop shop" approach and with its set of emerging quantitative imaging techniques such as T1, ECV and T2 mapping, DWI and FT is likely to gain more and more influence in the noninvasive diagnosis of MC. Most likely, the future diagnosis of MC by CMR will rely on a comprehensive multiparametric imaging approach, combining mapping techniques (either native T1, ECV or T2 or even two or three of them) with other diagnostic imaging parameters like LGE and FT or novel, emerging imaging methods, thereby changing or even replacing the traditional LLC.

As summarized in the present study, the diagnostic approach to $\mathrm{MC}$ is likely to undergo several changes in the near future, pointing towards an earlier and more accurate diagnosis of this highly relevant disease. If diagnosis can be made more reliably, novel therapeutic strategies will be able to evolve resulting in the prospect of more effective treatments for MC in the future - just like Sir William Osler stated in his "Principles and Practice of Medicine" already in 1892: "There are three phases to treatment: diagnosis, diagnosis and diagnosis."

\section{Affiliations}

Department of Radiology, University Hospital of Cologne, Germany

Department of Nuclear Medicine, University Hospital of Cologne, Germany

3 Diagnostic and Interventional Radiology, Herzzentrum Leipzig GmbH - University Clinic, Leipzig, Germany

4 Department of Internal Medicine/Cardiology, Herzzentrum Leipzig GmbH Universitatsklinik, Leipzig, Germany

5 Department of Cardiovascular Imaging, Universite Paris Diderot, Paris, France

Radiology, University of Cologne, Germany

\section{References}

1 Richardson P, McKenna W, Bristow M et al. Report of the 1995 World Health Organization/International Society and Federation of Cardiology Task Force on the Definition and Classification of cardiomyopathies. Circulation 1996; 93: $841-842$

2 Elamm C, Fairweather D, Cooper LT. Pathogenesis and diagnosis of myocarditis. Heart 2012; 98: $835-840$

3 Dennert R, Crijns HJ, Heymans S. Acute viral myocarditis. European Heart Journal 2008; 29: 2073-2082

4 Caforio ALP, Calabrese F, Angelini A et al. A prospective study of biopsyproven myocarditis: prognostic relevance of clinical and aetiopathogenetic features at diagnosis. European Heart Journal 2007; 28: 1326 1333

5 Hauck AJ, Kearney DL, Edwards WD. Evaluation of postmortem endomyocardial biopsy specimens from 38 patients with lymphocytic myocarditis: implications for role of sampling error. Mayo Clin. Proc 1989; 64: 1235 - 1245

6 Cooper LT, Baughman KL, Feldman AM et al. The role of endomyocardial biopsy in the management of cardiovascular disease: a scientific statement from the American Heart Association, the American College of Cardiology, and the European Society of Cardiology Endorsed by the Heart Failure Society of America and the Heart Failure Association of the European Society of Cardiology. Eur Heart J 2007; 28: 3076-3093

7 Caforio ALP, Pankuweit S, Arbustini E et al. Current state of knowledge on aetiology, diagnosis, management, and therapy of myocarditis: a position statement of the European Society of Cardiology Working Group on Myocardial and Pericardial Diseases. European Heart Journal 2013; 34: 2636 - 2648

8 Felker GM, Boehmer JP, Hruban RH et al. Echocardiographic findings in fulminant and acute myocarditis. Journal of the American College of Cardiology 2000; 36: 227-232

9 Pinamonti B, Alberti E, Cigalotto A et al. Echocardiographic findings in myocarditis. The American Journal of Cardiology 1988; 62: 285-291

10 Escher F, Kasner M, Kuhl U et al. New echocardiographic findings correlate with intramyocardial inflammation in endomyocardial biopsies of patients with acute myocarditis and inflammatory cardiomyopathy. Mediators Inflamm 2013; 2013: 875420-875429

11 Gorcsan J III, Tanaka H. Echocardiographic Assessment of Myocardial Strain. Journal of the American College of Cardiology 2011; 58: $1401-1413$

12 Hsiao JF, Koshino Y, Bonnichsen CR et al. Speckle tracking echocardiography in acute myocarditis. Int J Cardiovasc Imaging 2013; 29: 275-284

13 Di Bella G, Gaeta M, Pingitore A et al. Myocardial deformation in acute myocarditis with normal left ventricular wall motion-a cardiac magnetic resonance and 2-dimensional strain echocardiographic study. Circ J 2010; 74: 1205-1213

14 Khoo NS, Smallhorn JF, Atallah J et al. Altered left ventricular tissue velocities, deformation and twist in children and young adults with acute myocarditis and normal ejection fraction. Journal of the American Society of Echocardiography 2012; 25: 294-303

15 Løgstrup BB, Nielsen JM, Kim WY et al. Myocardial oedema in acute myocarditis detected by echocardiographic 2D myocardial deformation analysis. Eur Heart J Cardiovasc Imaging 2015; 17: 6, jev302

16 Muraru D, Cucchini $U$, Mihăilă S et al. Left ventricular myocardial strain by three-dimensional speckle-tracking echocardiography in healthy subjects: reference values and analysis of their physiologic and technical determinants. Journal of the American Society of Echocardiography 2014; 27: 858 -871.e1

17 Achenbach S, Barkhausen J, Beer M et al. Konsensusempfehlungen der DRG/DGK/DGPK zum Einsatz der Herzbildgebung mit Computertomo- 
grafie und Magnetresonanztomografie. Fortschr Röntgenstr 2012; 184: $345-368$

18 Lotz J. Leitlinien und Indikationen für die CT und MRT des Herzens. Fortschr Röntgenstr 2015; DOI: 10.1055/s-0036-1581350

19 Bruder O, Wagner A, Lombardi M et al. European Cardiovascular Magnetic Resonance (EuroCMR) registry - multi national results from 57 centers in 15 countries. Journal of Cardiovascular Magnetic Resonance 2013; $15: 9$

20 Gutberlet M, Lücke C, Krieghoff C et al. MRI for myocarditis. Der Radiologe 2013; 53: $30-37$

21 Friedrich MG, Sechtem U, Schulz-Menger J et al. Cardiovascular Magnetic Resonance in Myocarditis: A JACC White Paper. Journal of the American College of Cardiology 2009; 53: 1475-1487

22 Abdel-Aty $\mathrm{H}$, Boyé $P$, Zagrosek A et al. Diagnostic performance of cardiovascular magnetic resonance in patients with suspected acute myocarditis: comparison of different approaches. Journal of the American College of Cardiology 2005; 45: 1815-1822

23 Gutberlet M, Spors B, Thoma T et al. Suspected chronic myocarditis at cardiac MR: diagnostic accuracy and association with immunohistologically detected inflammation and viral persistence. Radiology 2008; 246: $401-409$

24 Lurz P, Eitel I, Adam J et al. Diagnostic performance of CMR imaging compared with EMB in patients with suspected myocarditis. JACC. Cardiovascular Imaging 2012; 5: 513-524

25 Laissy J-P, Messin B, Varenne $O$ et al. MRI of acute myocarditis: a comprehensive approach based on various imaging sequences. Chest 2002; 122: $1638-1648$

26 Mahrholdt H, Wagner A, Judd RM et al. Delayed enhancement cardiovascular magnetic resonance assessment of non-ischaemic cardiomyopathies. European Heart Journal 2005; 26: 1461 - 1474

27 Grün S, Schumm J, Greulich S et al. Long-term follow-up of biopsy-proven viral myocarditis: predictors of mortality and incomplete recovery. Journal of the American College of Cardiology 2012; 59: 1604-1615

28 Schumm J, Greulich S, Wagner A et al. Cardiovascular magnetic resonance risk stratification in patients with clinically suspected myocarditis. Journal of Cardiovascular Magnetic Resonance 2014; 16: 14

29 Giri S, Chung YC, Merchant A et al. T2 quantification for improved detection of myocardial edema. Journal of Cardiovascular Magnetic Resonance: Official Journal of the Society for Cardiovascular Magnetic Resonance 2009; 11: 56

30 Thavendiranathan $P$, Walls $M$, Giri S et al. Improved detection of myocardial involvement in acute inflammatory cardiomyopathies using T2 mapping. Circulation. Cardiovascular Imaging 2012; 5: 102-110

31 Hamlin SA, Henry TS, Little BP et al. Mapping the future of cardiac MR imaging: case-based review of T1 and T2 mapping techniques. Radiographics 2014; 34: 1594-1611

32 Wassmuth R, Prothmann M, Utz W et al. Variability and homogeneity of cardiovascular magnetic resonance myocardial T2-mapping in volunteers compared to patients with edema. Journal of Cardiovascular Magnetic Resonance 2013; 15: 27

33 Butler CR, Savu A, Bakal JA et al. Correlation of Cardiovascular MRI Findings and Endomyocardial Biopsy Results in Patients Undergoing Screening for Heart Transplant RejectionCardiovascular MRI and Heart Transplant Rejection. J Heart Lung Transplant 2015; 34: 643-650

34 Baeßler B, Schaarschmidt F, Stehning $C$ et al. A systematic evaluation of three different cardiac T2-mapping sequences at 1.5 and $3 \mathrm{~T}$ in healthy volunteers. European Journal of Radiology 2015; 84: 2161 - 2170

35 Baeßler B, Schaarschmidt F, Dick A et al. Mapping tissue inhomogeneity in acute myocarditis: a novel analytical approach to quantitative myocardial edema imaging by T2-mapping. Journal of Cardiovascular Magnetic Resonance 2015; 17: 67

36 Kellman P, Hansen MS. T1-mapping in the heart: accuracy and precision. Journal of Cardiovascular Magnetic Resonance 2014; 16: 2

37 Messroghli DRD, Radjenovic AA, Kozerke SS et al. Modified Look-Locker inversion recovery (MOLLI) for high-resolution T1 mapping of the heart. Magnetic Resonance in Medicine 2004; 52: 141-146

38 Moon JC, Messroghli DR, Kellman P et al. Myocardial T1 mapping and extracellular volume quantification: a Society for Cardiovascular Magnetic Resonance (SCMR) and CMR Working Group of the European Society of Cardiology consensus statement. Journal of Cardiovascular Magnetic Resonance 2013; 15: 92

39 Taylor AJ, Salerno M, Darmakumar R et al. T1 Mapping: Basic Techniques and Clinical Applications. JACC. Cardiovascular Imaging 2016; 9: $67-81$
40 Ferreira VM, Piechnik SK, Dall'Armellina E et al. T1 Mapping for the Diagnosis of Acute Myocarditis Using CMR: Comparison to T2-Weighted and Late Gadolinium Enhanced Imaging. JACC. Cardiovascular Imaging 2013; 6: 1048-1058

41 Hinojar R, Foote L, Arroyo UcarE et al. Native T1 in Discrimination of Acute and Convalescent Stages in Patients With Clinical Diagnosis of Myocarditis: A Proposed Diagnostic Algorithm Using CMR. JACC. Cardiovascular Imaging 2015; 8: 37-46

42 Radunski UK, Lund GK, Stehning C et al. CMR in Patients With Severe Myocarditis: Diagnostic Value of Quantitative Tissue Markers Including Extracellular Volume Imaging. JACC Cardiovascular Imaging 2014; 7: $667-675$

43 Bohnen S, Radunski UK, Lund GK et al. Performance of t1 and t2 mapping cardiovascular magnetic resonance to detect active myocarditis in patients with recent-onset heart failure. Circulation. Cardiovascular Imaging 2015; 8: e003073

44 Luna A, Ribes R, Soto JA. Diffusion MRI Outside the Brain, Berlin, Heidelberg. Springer Science \& Business Media 2011: 279-306

45 Potet J, Rahmouni A, Mayer J et al. Detection of Myocardial Edema with Low-b-value Diffusion-weighted Echo-planar Imaging Sequence in Patients with Acute Myocarditis. Radiology 2013; 269: 362 - 369

46 Hor KN, Baumann R, Pedrizzetti G et al. Magnetic Resonance Derived Myocardial Strain Assessment Using Feature Tracking. JoVE 2011; 48

47 Blessberger $H$, Binder T. NON-invasive imaging: Two dimensional speckle tracking echocardiography: basic principles. Heart 2010; 96: 716-722

48 Baeßler B, Schaarschmidt F, Dick A et al. Diagnostic implications of magnetic resonance feature tracking derived myocardial strain parameters in acute myocarditis. European Journal of Radiology 2016; 85: 218 227

49 Dambrin G, Laissy JP, Serfaty JM et al. Diagnostic value of ECG-gated multidetector computed tomography in the early phase of suspected acute myocarditis. A preliminary comparative study with cardiac MRI European Radiology 2007; 17: 331 - 338

50 Boussel L, Gamondes D, Staat P et al. Acute chest pain with normal coronary angiogram: role of contrast-enhanced multidetector computed tomography in the differential diagnosis between myocarditis and myocardial infarction. Journal of Computer Assisted Tomography 2008; 32: 228-232

51 Danad I, Fayad ZA, Willemink MJ et al. New Applications of Cardiac Computed Tomography: Dual-Energy, Spectral, and Molecular CT Imaging. JACC. Cardiovascular Imaging 2015; 8: 710-723

52 Baudry G, Bouleti C, Iung B et al. Diagnosis of acute myocarditis with dual source cardiac tomography. Int J Cardiol 2015; 179: 256-257

53 Terzian Z, Henry-Feugeas M-C, Billebeau G et al. Spectral contrast-enhanced cardiac computed tomography for diagnosis of acute myocarditis. Can J Cardiol 2015; 31: 691.e9-691.e10

54 Treibel TA, Bandula S, Fontana $M$ et al. Extracellular volume quantification by dynamic equilibrium cardiac computed tomography in cardiac amyloidosis. J Cardiovasc Comput Tomogr 2015; 0: 585-592

55 Laganà B, Schillaci $O$, Tubani L et al. Lupus carditis: evaluation with technetium-99m MIBI myocardial SPECT and heart rate variability. Angiology 1999; 50: 143-148

56 Bengel F, Burchert W, Hacker M et al. DGN: S1-Leitlinie Myokard-Perfusions-Szintigrafie (Reg-Nr. 031-006); 2012: 1-50

57 Miyagawa M, Yokoyama R, Nishiyama $Y$ et al. Positron Emission Tomography-Computed Tomography for Imaging of Inflammatory Cardiovascular Diseases. Circ. J 2014; 78: $1302-1310$

58 Dilsizian V, Bacharach SL, Beanlands RS et al. PET myocardial perfusion and metabolism clinical imaging. J Nucl Cardiol 2009; 16: 651 -651

59 Ozawa K, Funabashi N, Daimon $M$ et al. Determination of optimum periods between onset of suspected acute myocarditis and 18F-fluorodeoxyglucose positron emission tomography in the diagnosis of inflammatory left ventricular myocardium. Int J Cardiol 2013; 169: $196-200$

60 Takano $\mathrm{H}$, Nakagawa $\mathrm{K}$, Ishio $\mathrm{N}$ et al. Active myocarditis in a patient with chronic active Epstein-Barr virus infection. Int J Cardiol 2008; 130: e11-e13

61 Erba PA, Sollini M, Lazzeri $E$ et al. FDG-PET in cardiac infections. Semin Nucl Med 2013; 43: 377-395

62 Baeßler B, Schaarschmidt F, Stehning C et al. Cardiac T2-mapping using a fast gradient echo spin echo sequence -- first in vitro and in vivo experience. Journal of Cardiovascular Magnetic Resonance 2015; 17: 67 